\title{
Descrição de rótulos de medicamentos como estratégia para identificação de medicamentos falsificados
}

\author{
Description of drug labels as a strategy for \\ identification of counterfeit medicines
}

Recebido em: 31/01/2019 Aceito em: $\quad 10 / 06 / 2019$

\author{
Augusto Santana Palma SILVA ${ }^{1}$; Sheila Torres Feitosa SILVA ${ }^{2}$ \\ ${ }^{1}$ Universidade Federal do Vale do São Francisco. \\ Av. José de Sá Maniçoba, S/N, Centro, CEP 56304-917. Petrolina, PE, Brasil. \\ ${ }^{2}$ Universidade Norte do Paraná. R. Argentina, 217, Coreia, \\ CEP 48904-450. Juazeiro, BA, Brasil. \\ E-mail: augustolestat@gmail.com
}

\section{ABSTRACT}

Counterfeit medicines pose a public health problem by exposing the population to risks related to the use of products with unverifiable quality and safety. The fight against its trade is part of a Sanitary Surveillance action strategy, an organ in which the pharmacist plays an important role related to the identification of these, action extendable to other population segments. The present study aims to describe the labels of seized products evidencing variables that are easy to identify and indicative of unlawfulness by non-pharmacists. The seizures carried out by the inspection team occurred in drugstores located in the municipality of Macroregion Northeast Brazil following the main legislation in force on the subject. Of the four products seized, two were presented as vegetable oils, one as a cosmetic and the other as a food supplement. Vegetable oils presented false information about the manufacturer, and the others did not present information about it. All presented therapeutic purposes or actions, in disagreement with sanitary legislation. Variables related to the producer, composition, and purpose of use of the product may comprise a strategy for expanding enforcement actions related to counterfeit products, considering educational and guiding actions for drug store owners and drug users. It is evident the importance of the appropriation of knowledge by the agents, directly and indirectly, involved in the therapeutic chain, in line with the guidelines of Law No. 8.080, of September 19, 1990, which treats health as direct of all and duty of the State without, however, exclude from membership in society their respective duties to the health of others.

KEYWORDS: health surveillance; falsification; health education.

\section{RESUMO}

Medicamentos falsificados configuram problema de Saúde Pública ao expor a população a riscos relacionados ao uso de produtos com qualidade e segurança não verificáveis. O combate ao seu comércio compõe estratégia de ações da Vigilância Sanitária, órgão no qual o farmacêutico ocupa importante papel relacionado à identificação destes, ação extensível aos demais segmentos populacionais. O presente estudo tem com objetivo a descrição de rótulos de produtos apreendidos, evidenciando variáveis de fácil identificação e indicativa de ilicitudes por parte de não farmacêuticos. As apreensões realizadas pela equipe fiscalizadora ocorreram em drogarias situadas em município da Macrorregião Nordeste Brasileira em conformidade 
com as principais legislações vigentes acerca do tema. Dos quatro produtos apreendidos, dois referiam-se a óleo vegetal, um a cosmético e outro a suplemento alimentar. Óleos vegetais apresentaram informações falsas sobre o fabricante e os demais não apresentaram informações sobre o mesmo. Todos apresentaram finalidades ou ações terapêuticas, em não-conformidade às legislações sanitárias. Variáveis relacionadas ao fabricante, composição e finalidade de uso do produto podem compor estratégia de ampliação das ações fiscalizadoras relacionadas a produtos falsificados, ao se considerar ações de cunho educativo e orientador a proprietários de drogarias e usuários de medicamentos. É evidente a importância da apropriação do conhecimento por parte dos agentes, direta e indiretamente, envolvidos na cadeia terapêutica, em sintonia às diretrizes da Lei $\mathrm{n}^{\circ}$ 8.080, de 19 de setembro de 1990, que trata a saúde como direto de todos e dever do Estado sem, contudo, excluir de membros da sociedade seus respectivos deveres para com a saúde de outrem.

PALAVRAS-CHAVE: vigilância sanitária; falsificação; educação sanitária.

\section{INTRODUÇÃO}

Medicamentos falsificados, entendidos como aqueles embalados e etiquetados incorretamente (fraudulenta e deliberadamente) onde não são respeitados fontes ou identidade do produto, configuram grave problema de Saúde Pública uma vez que expõem a população a riscos atrelados a critérios de não segurança e qualidade (1). O combate ao seu comércio, de difícil realização em regiões cuja regulamentação e aplicação de estratégias fiscalizadoras apresentam fragilidades (2), é um eixo estratégico de atuação de órgãos de Vigilância Sanitária, tendo na figura do farmacêutico seu principal e indispensável profissional, visto ser privativa deste a fiscalização profissional, técnica e sanitária de estabelecimentos de interesse à saúde onde ocorre o comércio de medicamentos (3).

Tão importante quanto o incremento de ações fiscalizadoras, atitudes de natureza educativa (que podem ter sua ocorrência em momentos diversos em relação ao processo fiscalizatório) que alertem aos efeitos prejudiciais à saúde, bem como instruam a população no tocante a permitir a identificação de medicamentos ilícitos, devem ser consideradas como variáveis aditivas ao processo, assegurando uma maior capilaridade das ações fiscalizadoras (2). Desta maneira, o presente estudo descreve rótulos de produtos apreendidos por uma equipe de fiscais de uma Agência Municipal de Vigilância Sanitária a fim de fornecer exemplos reais de informações que permitam a profissionais, proprietários e população usuária de estabelecimentos farmacêuticos a identificação de irregularidades características de um produto que contraria a legislação sanitária pertinente acerca de medicamentos.

\section{MÉTODOS}

A amostra referiu-se a quatro produtos apreendidos em drogarias localizadas em um município da Macrorregião Nordeste brasileira, com população estimada em 343.865 indivíduos em 2018 (dados do censo de 2010 apontaram um quantitativo igual a 293.962 pessoas), cuja densidade demográfica, para o ano de 2010 fora de 64,44 habitantes por quilômetro quadrado (considerando uma área territorial igual a $4.561,870 \mathrm{~km}^{2}$ ).

As apreensões, asseguradas pela Lei Federal $n^{\circ}$ 6.437, de 20 de agosto de 1977 (4), ocorreram uma vez identificadas inconformidades na forma de: a) ausência de registro junto ao Ministério da Saúde e/ou; b) rotulagem contendo informações que contrariassem a legislação sanitária vigente. Foram consideradas as diretrizes legais estipuladas pelas Resoluções da Diretoria Colegiada (RDC) $n^{\circ} 27$, de 06 de agosto de 2010 (5) e no 243, de 26 de julho de 2018 (6), bem como a Lei Federal $n^{\circ}$ 6.360, de 23 de setembro de 1976 (7). As apreensões foram realizadas durante inspeção realizada no mês de dezembro de 2018, por equipe composta por um farmacêutico, um agente de inspeção sanitária e dois estudantes em período de estágio curricular obrigatório. Após apreensão, foram transcritas as informações referents a: a) a natureza do produto (suplemento alimentar, cosmético ou óleo de origem vegetal); b) dados do fabricante - ausência ou pre- 
sença de Razão Social e ou CNPJ (posteriormente verificados junto ao sitio do Ministério da Fazenda) (8); c) indicações de uso e; d) composição do produto. Esses dados estão apresentados no Quadro 1.

\section{RESULTADOS E DISCUSSÃO}

Dos quatro produtos apreendidos, um (Produto 1 - P1) era suplemento alimentar, dois (P2 e P3), óleo de origem vegetal e um (P4), cosmético. Dois deles (P2 e P3) não apresentaram, em seus rótulos, informações referentes ao fabricante; os demais (P1 e P4) apresentaram informações falsas (número de inscrição de CNPJ não foi localizado no site do Ministério da Fazenda) (8). Todos apresentaram indicações de uso (com a utilização de linguagem coloquial), e em dois deles (P3 e P4), a indicação em questão correspondia aos nomes dos produtos. Os produtos $\mathrm{P} 1$ e $\mathrm{P} 4$ apresentaram informações referentes às suas respectivas composições, ao passo que P2 e P3 não. As respectivas indicações, bem como a composição dos produtos apreendidos podem ser visualizados no Quadro 1.

Apesar de isentos de registro, a conforme Resolução da Diretoria Colegiada (RDC) no 27, de 6 de agosto de 2010, da Agência Nacional de Vigilância Sanitária (Anvisa) (5), suplementos alimentares e óleos de origem vegetal não podem conter informações que possam sugerir ou implicar que os mesmos possuem finalidades ou indicações terapêuticas ou medicamentosas, visto que isso contraria as diretrizes legais da $\mathrm{RDC} \mathrm{n}^{\circ} 243$, de 26 de julho de 2018 (6). Ainda, cosméticos devem possuir em seus rótulos informações referentes ao registro junto ao Ministério de Saúde, em função do preconizado pela Lei Federal $n^{\circ} 6.360$, de 23 de setembro de 1976 (7).

Os resultados vão ao encontro daqueles apontados por Marcheti, que não apenas sinalizou o incremento do comércio de medicamentos falsificados no País, mas também evidenciou ser a rotulagem uma das principais variáveis de ocorrência de ilicitudes (9).

Apesar da não realização de testes analíticos (e, portanto, não ser possível a determinação físico-química dos produtos apreendidos), convém salientar que a falsificação de medicamentos configura grave problema da Saúde Pública em função da não garantia da segurança e qualidade dos mesmos, o que pode resultar no tratamento não adequado de uma determinada enfermidade. Por sua vez, isto pode apresentar como desfechos: a) agravamento da condição de morbidade ou; b) óbito do paciente (9). Não obstante, existe relação entre o consumo de medicamentos falsificados e o desenvolvimento de resistência a fármacos (10).

Quadro 1. Descrições presentes em rótulos dos produtos apreendidos em drogarias durante exercício da equipe fiscalizadora de vigilância sanitária em município localizado na Macrorregião Nordeste do Brasil.

\begin{tabular}{|c|c|c|c|}
\hline Produto & Natureza & Descrição do rótulo ${ }^{1}$ & Composição $^{1}$ \\
\hline P1 & Suplemento Alimentar & $\begin{array}{l}\text { combate eficazmente doenças do estômago, do fíga- } \\
\text { do, do intestino, Ácido Úrico, Diabete, mau hálito, } \\
\text { boca amarga, gases, obesidade, cálculo na vesícula } \\
\text { e nos rins, má digestão, manchas da pele, reduz o } \\
\text { colesterol, controla a pressão arterial, é dupartivo } \\
\text { do sangue, vermífugo e acalma o sistema nervoso }\end{array}$ & $\begin{array}{l}\text { carqueja, pina, para-tudo, juru- } \\
\text { beba, espinheira santa, boldo, } \\
\text { camomila, cipó-cabeludo, cha- } \\
\text { peu [sic]* de couro e pacari }\end{array}$ \\
\hline $\mathbf{P 2}$ & Óleo vegetal & Cicatrizante $[\mathrm{sic}]^{*}$ corte e feridas & Não informado \\
\hline P3 & óleo vegetal & $\begin{array}{l}\text { contra dores musculares, colunal [sic], dor de cabe- } \\
\text { ça, dor de dente, cólica abdominal, dores reumáti- } \\
\text { cas, torções, sinusite, asma etc [sic]. }\end{array}$ & Não informado \\
\hline P4 & Cosmético & $\begin{array}{l}\text { Analgésico, anti-inflamatório, cicatrizante - refres- } \\
\text { cante, hidratante } \mathrm{p} /[\mathrm{sic}]^{*} \text { rachaduras }\end{array}$ & $\begin{array}{l}\text { carbopol, álcool isop, propileno } \\
\text { glicol, trieta, metil parabeno, } \\
\text { propil parabeno e água desmine- } \\
\text { ralizada (Composição Ativa) sebo } \\
\text { de carneiro, andiroba, mentol, } \\
\text { cânfora chinesa, salicilato de } \\
\text { metila, centelha asiástica, arnica } \\
\text { e castanha da índia }\end{array}$ \\
\hline
\end{tabular}

* [sic] indica erro na forma da grafia do termo ou de pontuação gramatical; ${ }^{1}$ Transcrição das informações presents no rótulo 
Informações simples e facilmente verificáveis - dados do fabricante, composição e indicação de uso (este em particular) - podem ser utilizadas como indicadores para identificação de produtos irregulares o que, espera-se, não passe despercebido aos olhos do profissional farmacêutico responsável técnico pelo estabelecimento de saúde.

Curiosamente, as apreensões ocorreram em drogarias nas quais os farmacêuticos não se encontravam durante a ação da equipe fiscalizadora, corroborando aos dados obtidos por Hurtado e Lasmar, onde $90 \%$ dos estabelecimentos inspecionados não contavam com a presença física do profissional que assumia a responsabilidade técnica pelo mesmo (1). Se, por um lado, há a necessidade de um papel ainda mais ativo deste profissional, por outro é sinalizada a importância de o mesmo estar presente durante todo o horário de funcionamento do estabelecimento, visto o seu potencial como agente ativo no que se refere a interromper a cadeia de comércio de medicamentos irregulares (aquisição e posterior venda). Não obstante, os resultados evidenciam um potencial campo de atuação de profissionais (Vigilância Sanitária e/ou farmacêuticos responsáveis técnicos por estabelecimentos e/ou demais órgãos competentes) relacionados à orientação de proprietários quanto à capacidade de identificar produtos ilícitos (2), real objeto do estudo. Medicamentos falsificados, e seu comércio, são uma realidade em drogarias brasileiras e, apesar do período de análise e universo amostral serem razoavelmente curtos, o presente estudo justifica a si mesmo por ratificar a importância de adoção de medidas simples, eficazes e efetivas no tocante a assegurar o combate a este tipo de medicamentos (2).

A capacidade de identificação de medicamentos irregulares, seja por parte do profissional fiscalizador, proprietários de estabelecimentos farmacêuticos, responsáveis técnicos ou mesmo consumidores finais apresenta elevado potencial de combate ao comércio destes produtos, ampliando a rede de atuação de equipes fiscalizadoras e atuando como mecanismo compensatório de fragilidades naturais existentes e inerentes ao sistema de saúde (11).

O presente estudo ratifica a importância da apropriação do conhecimento por parte dos agentes direta (proprietários e farmacêutico) e indiretamente (consumidores finais) envolvidos na cadeia terapêutica, em sintonia às diretrizes da Lei $\mathrm{n}^{\circ} 8.080$, de 19 de setembro de 1990 (12), que trata a saúde como direto de todos e dever do Estado sem, contudo, excluir das pessoas, família, empresas e sociedade seus respectivos deveres para com a saúde de outrem.

\section{AGRADECIMENTOS}

Os autores agradecem à Agência Municipal de Vigilância Sanitária por permitir o uso das informações referentes aos produtos apreendidos.

\section{REFERÊNCIAS}

1. Hurtado RL, Lasmar MC. Medicamentos falsificados e contrabandeados no Brasil: panorama geral e perspectivas de combate ao seu consumo. Cad. Saúde Pública. 2014;30(4):891-895. DOI: 10.1590/0102311X00107013

2. Ames J, Souza DZ. Falsificação de medicamentos no Brasil. Rev. Saúde Pública. 2012;46(1):154-159.

3. CFF. Conselho Federal de Farmácia. Resolução CFF no 539, de 22 de outubro de 2010. Dispõe sobre o exercício profissional e as atribuições privativas e afins do farmacêutico nos Órgãos de Vigilância Sanitária, e dá outras providências. Brasília: CFF; 2010.

4. BRASIL. Lei $n^{\circ} 6.437$, de 20 de agosto de 1977. Configura infrações à legislação sanitária federal, estabelece as sanções penais respectivas e dá outras providências. Brasília, DF; 1977.

5. ANVISA. Resolução da Diretoria Colegiada $n^{\circ} 27$, de 06 de agosto de 2010. Dispõe sobre as categorias de alimentos e embalagens isentos e com obrigatoriedade de registro sanitário. Agência Nacional de Vigilância Sanitária. Brasília, DF: 2010.

6. ANVISA Resolução da Diretoria Colegiada n ${ }^{\circ} 243$, de 26 de julho de 2018. Dispõe sobre os requisitos sanitários dos suplementos alimentares. Agência Nacional de Vigilância Sanitária. Brasília, DF: 2018.

7. BRASIL. Lei ${ }^{\circ} 6.360$, de 23 de setembro de 1976. Dispõe sobre a vigilância sanitária a que ficam sujeitos os medicamentos, as drogas, os insumos farmacêuticos e 
correlatos, cosméticos, saneantes e outros produtos, e dá outras providências. Brasília, DF; 1976.

8. BRASIL. Receita Federal - Ministério da Fazenda. [citado em 10 de março de 2019]. Disponível em https:// www.receita.fazenda.gov.br/pessoajuridica/cnpj/cnpjreva/cnpjreva_solicitacao2.asp.

9. Marcheti RGA. Avaliação da falsificação de medicamentos a partir dos dados de laudos periciais do departamento de Polícia Federal no Brasil no período de 2006 a 2012. [Dissertação]. Brasília: Faculdade de Ciências da Saúde, Universidade de Brasília. 2014.
10. Chokshi A, Sifri Z, Cennimo D, Horng H. Global contributors to antibiotic resistance. J Global Infect Dis 2019; 11(1):36-42.

11. Fantasia HC, Vooys KM. Public Health implications of counterfeit medications. Nurs Women's Health 2018; 22(3):264-268. DOI: 10.1016/j.nwh.2018.03.001.

12. BRASIL. Lei ${ }^{\circ} 8.080$, de 19 de setembro de 1990. Dispõe sobre as condições para a promoção, proteção e recuperação da saúde, a organização e o funcionamento dos serviços correspondentes, e dá outras providências. Brasília, DF; 1990. 